Biogeosciences, 10, 2815-2819, 2013

www.biogeosciences.net/10/2815/2013/

doi:10.5194/bg-10-2815-2013

(C) Author(s) 2013. CC Attribution 3.0 License.

(c) (i)

\title{
The real limits to marine life: a further critique of the Respiration Index
}

\author{
B. A. Seibel ${ }^{1}$ and J. J. Childress ${ }^{2}$ \\ ${ }^{1}$ Biological Sciences, University of Rhode Island, Kingston, RI 02881, USA \\ ${ }^{2}$ Ecology, Evolution and Marine Biology, University of California, Santa Barbara, CA, USA \\ Correspondence to: B. A. Seibel (seibel@uri.edu) and J. J. Childress (childres@lifesci.ucsb.edu) \\ Received: 7 October 2012 - Published in Biogeosciences Discuss.: 20 November 2012 \\ Revised: 21 March 2013 - Accepted: 8 April 2013 - Published: 2 May 2013
}

\begin{abstract}
The recently proposed "Respiration Index" $\left(\mathrm{RI}=\log P_{2} / \mathrm{PCO}_{2}\right)$ suggests that aerobic metabolism is limited by the ratio of reactants (oxygen) to products (carbon dioxide) according to the thermodynamics of cellular respiration. Here, we demonstrate further that, because of the large standard free energy change for organic carbon oxidation $\left(\Delta G^{\circ}=-686 \mathrm{kcal} \mathrm{mol}^{-1}\right)$, carbon dioxide can never reach concentrations that would limit the thermodynamics of this reaction. A $P \mathrm{CO}_{2}$ to $P \mathrm{O}_{2}$ ratio of $10^{503}$ would be required to reach equilibrium (equilibrium constant, $K_{\text {eq }}=10^{503}$ ), where $\Delta G=0$. Thus, a Respiration Index of -503 would be the real thermodynamic limit to aerobic life. Such a Respiration Index is never reached, either in the cell or in the environment. Moreover, cellular respiration and oxygen provision are kinetically controlled such that, within limits, environmental oxygen and $\mathrm{CO}_{2}$ concentrations have little to do with intracellular concentrations. The RI is fundamentally different from the aragonite saturation state, a thermodynamic index used to quantify the potential effect of $\mathrm{CO}_{2}$ on calcification rates, because of its failure to incorporate the equilibrium constant of the reaction. Not only is the RI invalid, but its use leads to incorrect and misleading predictions of the threat of changing oxygen and carbon dioxide to marine life. We provide a physiological framework that identifies oxygen thresholds and allows for synergistic effects of ocean acidification and global warming.
\end{abstract}

\section{Introduction}

Growing evidence suggests that oxygen minimum zones are expanding, while ocean acidification is well-documented (Feely et al., 2008; Stramma et al., 2008; Keeling et al., 2010; Bograd et al., 2008). The possible biological effects of these climate-induced changes are well characterized (Seibel and Fabry, 2003; Melzner et al., 2009; Pörtner and Knust, 2007; Childress and Seibel, 1998; Seibel, 2011; Hochachka and Somero, 2002), but no single metric has been identified that facilitates straightforward ecological predictions relating to climate change in the marine environment. A recent paper by Brewer and Peltzer (2009) proposes a "Respiration Index" that purports to quantify the combined effects of carbon dioxide and oxygen partial pressures on the aerobic metabolism of marine organisms. The RI is based on the idea that the energy available to perform work $(\Delta G)$, obtained from cellular respiration, is directly related to the partial pressures of oxygen and carbon dioxide in seawater, as if the reaction were taking place in a closed system and moving toward equilibrium.

$\mathrm{C}_{\text {org }}+6 \mathrm{O}_{2} \leftarrow \rightarrow 6 \mathrm{CO}_{2}+6 \mathrm{H}_{2} \mathrm{O}$

They express this as a Gibbs free energy equation,

$\Delta G=\Delta G^{\circ}+\mathrm{RT} \cdot \ln K_{\mathrm{eq}}$,

where $K_{\mathrm{eq}}$ is the equilibrium constant equivalent of the ratio of products (e.g., $\mathrm{PCO}_{2}$ ) to reactants (e.g., $P \mathrm{O}_{2}$ ), $\Delta G$ is the Gibbs free energy defined as the energy available to do work, and $\Delta G^{\circ}$ is the standard free energy defined as the free energy at standard temperature and where the concentrations of products equal reactants. Brewer and Peltzer (2009) defined 
the Respiration Index, RI, as the ratio of the partial pressures of reactants to products, a metric of the presumed direct effect of these concentrations on $\Delta G$.

$\mathrm{RI}=\log P \mathrm{O}_{2} / P \mathrm{CO}_{2}$

Note that Brewer and Peltzer inverted the ratio of products to reactants from Eq. (1) to eliminate the negative sign that was erroneously inserted in their formulation of the Gibbs equation. Equation (2) is correct as written above, but we retain the inversion for consistency with their paper.

The RI is alluring because of its simplicity and apparent mechanistic underpinnings. However, Brewer and Peltzer's suggestion that the RI can present a thermodynamic limit to aerobic life is simply incorrect and reveals a fundamental misunderstanding of thermodynamics and of animal physiology. We argue here, based on well-studied bioenergetic considerations, that this ratio is irrelevant and that cellular metabolism is irreversible and tightly regulated in the cell. As a result, the energy obtained from the oxidation of organic matter is effectively independent of environmental gas concentrations.

\section{$2 \Delta G$ of $\mathrm{C}_{\mathrm{org}}$ oxidation and the $K_{\mathrm{eq}}$}

Brewer and Peltzer suggest that a RI of 0 (i.e., $P_{2}: p \mathrm{CO}_{2}=$ 1) represents a thermodynamic limit to aerobic metabolism as if the reaction were at equilibrium when $P_{2}$ is equal to $P \mathrm{CO}_{2}$. However, $\Delta G$ does not equal zero, and the reaction is not near equilibrium, when the RI is zero. Rather, an RI of zero at $25^{\circ} \mathrm{C}$ is the definition of standard conditions, where $\Delta G=\Delta G^{\circ}$ (Eq. 1, Fig. 1). The $\Delta G^{\circ}$ for glucose oxidation is equal to $-686 \mathrm{kcal} \mathrm{mol}^{-1}$ (Lehninger, 2008). This means that glucose oxidation is an extremely exergonic reaction that is very far from equilibrium under standard conditions, when $P \mathrm{CO}_{2}=\mathrm{PO}_{2}(\mathrm{RI}=0)$. Under these standard conditions, oxidation of $\mathrm{C}_{\text {org }}$ is still a highly favorable reaction with tremendous potential for energy extraction (Fig. 1). Brewer and Peltzer (2009) appear to confuse equilibrium $(\Delta G=0$ and $\left.\mathrm{RI} \sim K_{\text {eq }}\right)$ with standard conditions $\left(\Delta G=\Delta G^{\circ}\right.$ and $\left.\mathrm{RI}=0\right)$.

The oxidation of organic carbon remains energetically favorable across all realistic $\mathrm{CO}_{2}$ partial pressures, whether intracellular or environmental. Inserting the value for $\Delta G^{\circ}$ for Glucose into the Gibbs equation, we calculate the ratio of products to substrates at equilibrium (the equilibrium constant, $K_{\text {eq }}$ ), which is the actual absolute thermodynamic limit to aerobic life as envisioned by Brewer and Peltzer (2009), ignoring kinetic control of metabolic processes. At equilibrium, $\Delta G=0$ and no free energy is available from the reaction to perform work. In that case, the Gibbs equation simplifies.

$-\Delta G^{\circ} / \mathrm{RT}=\ln K_{\mathrm{eq}}$,

where $R=1.987 \mathrm{cal} \mathrm{mol}^{-1} \mathrm{~K}^{-1}$ (note that $\Delta G^{\circ}$ is in kcal $\mathrm{mol}^{-1}$ ), and $T=298 \mathrm{~K}$. We calculate a $K_{\text {eq }}$ of $10^{503}$.

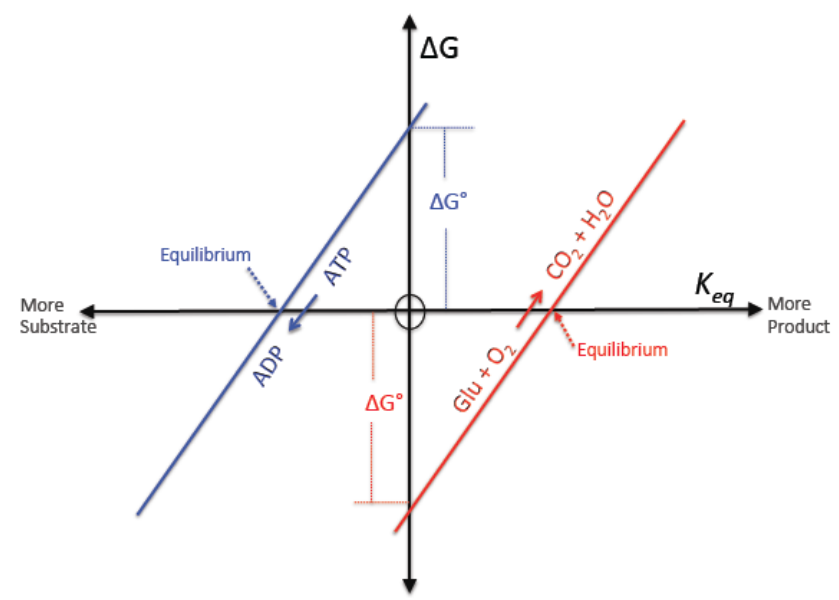

Fig. 1. A schematic illustrating the relationship between the free energy change $(\Delta G)$, the free energy change under standard conditions $\left(\Delta G^{\circ}\right)$, and the equilibrium constant $\left(K_{\text {eq }}\right)$. At equilibrium ( $\Delta G=0$ ), the glucose (Glu) oxidation reaction (red line) is shifted far to the right, resulting in a high $K_{\text {eq }}\left(10^{503}\right.$, ratio of product, $\mathrm{CO}_{2}$, to reactant, $\left.\mathrm{O}_{2}\right) . \Delta G^{\circ}$ for glucose oxidation is very large and negative $\left(-689 \mathrm{kcal} \mathrm{mol}^{-1}\right)$ meaning that, under standard conditions $\left(K_{\text {eq }}=1\right)$, the reaction is highly favored in the forward direction. The energy derived from this highly exergonic reaction is used to drive the synthesis of ATP (blue line), a highly endergonic and unfavorable reaction.

That is, at equilibrium when $\Delta G=0$, the ratio of $\mathrm{CO}_{2}: \mathrm{O}_{2}$ would be $10^{503}$, equivalent to a RI of -503 . Even when coupled to ATP synthesis, a highly endergonic reaction, the effective $K_{\text {eq }}$ is $\sim 10^{170}$. Obviously this value is never obtained in the cell or in the environment, and the RI is thus completely invalid and provides no useful information. This is the reason that biologists have ignored the $\mathrm{CO}_{2}$ side of the respiration equation, not "on the unspoken assumption that $\mathrm{PCO}_{2}$ levels are low and are inversely proportional to the $\mathrm{O}_{2}$ concentration" as asserted by Brewer and Peltzer.

In an earlier rebuttal, Brewer and Peltzer asserted that thermodynamic indices are in wide use, pointing to the saturation state for $\mathrm{CaCO}_{3}$ ( $\Omega$, Eq. 4), providing an index of the ability of marine organisms to produce calcareous shells, as a recent and relevant example. Why is the RI different from the aragonite saturation state? To the extent that calcification and cellular metabolism are both kinetically controlled processes carried out as open systems, the aragonite saturation state does suffer some of the same problems faced by the $\mathrm{RI}$ and is, at best, a rough predictor of the response of calcifying organisms to ocean acidification (Ries et al., 2009). However, unlike the Respiration Index, the aragonite saturation state incorporates the equilibrium characteristics of the reaction (i.e., the solubility product, $K_{\mathrm{sp}}$ ) and the concentrations of carbonate and calcium ions in seawater are near the equilibrium value such that ocean acidification can have an impact on the reaction. Moreover, the reaction is reversible and the back reaction, $\mathrm{CaCO}_{3}$ dissolution, often occurs in 
direct contact with seawater and is not kinetically controlled. Thus, the aragonite saturation state is a valid, albeit imprecise, thermodynamic index.

$\Omega=\left[\mathrm{Ca}^{2+}\right]\left[\mathrm{CO}_{3}^{2-}\right] / K_{\mathrm{sp}}$

The formulation that Brewer and Peltzer appeared to strive for would be $\mathrm{RI}=\left(\left(\mathrm{PCO}_{2} / P \mathrm{O}_{2}\right) / K_{\text {eq }}\right)$. When such a metric approaches $1, \Delta G$ is zero and no net energy is obtainable from cellular respiration. However, such a condition is only met in nature when oxygen is well below the limits of detection and beyond the extraction capabilities of any organism. Even so, the effect of ocean acidification on the thermodynamics of cellular respiration would be negligible. Carbon dioxide does influence organismal metabolism, but only indirectly (see below).

\section{Kinetic and physiological control of organismal metabolism}

Even if one ignores the thermodynamic considerations above, the RI is completely irrelevant. The RI assumes that the gas partial pressures inside the cell are equivalent to those in the environment when, in fact, they are quite different. The differences exist, not only because of differing solubilities between $\mathrm{CO}_{2}$ and $\mathrm{O}_{2}$, but because organisms maintain, within physiological limits, gas partial pressures at levels consistent with basic cellular function regardless of the partial pressures in the environment. For example, by comparing aquatic and terrestrial organisms it becomes clear that intracellular gas levels are actively maintained, rather than passively reflective of environmental conditions. Because oxygen is not limiting in air, the rate of ventilation can be much lower in air-breathers and carbon dioxide can build up to very high partial pressures $(5 \mathrm{kPa})$. Intracellular concentrations of gases are regulated by independent physiological mechanisms, and physiological limits at the whole-organism level result from constraints on oxygen supply and acid-base regulation. These vary widely between species. These kinetic objections were raised in an earlier critique (Seibel et al., 2009).

The RI does not distinguish between intracellular and environmental gas partial pressures. This distinction is important because marine organisms adapted to hypoxic environments can obtain sufficient oxygen regardless of the RI, via enhanced oxygen extraction capabilities. Active ventilation across high surface area gills and rapid circulation of blood with high-affinity respiratory proteins ensures a sufficient gradient of oxygen from the seawater to the sites of cellular respiration (Childress and Seibel, 1998; Sanders and Childress, 1990; Seibel, 2013). The acid-base balance can be actively adjusted to enhance oxygen release at the respiring tissues. The oxygen affinities of enzyme complexes in metabolic pathways also contribute to oxygen flux (Connett et al., 1990). Gradients may also be influenced by substituting cellular constituents with different solubilities for oxygen and carbon dioxide. For example, oxygen is highly soluble in lipids such that increasing intracellular lipid stores has been shown to enhance oxygen diffusion (Sidell, 1998). Via such mechanisms, the concentration of oxygen can actually be higher in the tissues than in the environment, as is observed in oxygen-filled swim bladders and in the eyes of fishes (Pelster, 2001). At oxygen partial pressures above a critical limit $\left(P_{\text {crit }}\right)$, intracellular partial pressures may be independent of environmental partial pressures because the blood (in those species with respiratory proteins) remains fully saturated with oxygen (Seibel, 2011).

\section{Physiological effects of hypercapnia}

Elevated carbon dioxide (hypercapnia) may decrease (Seibel et al., 2012) or increase (Stumpp et al., 2011) organismal metabolism. These effects are often mediated by available energy, but not via the thermodynamic mechanism proposed by Brewer and Peltzer. Depending on the buffering capacity of intra- and extracellular fluids and on the capacity of organisms to compensate via transport of acid-base equivalents, elevated $\mathrm{CO}_{2}$ will acidify tissues just as it does seawater (Seibel and Fabry, 2003; Melzner et al., 2009). This may have important implications for protein function, among other things (Hochachka and Somero, 2002). One well-studied effect of $\mathrm{CO}_{2}$ on organismal function is on the oxygentransport capacity via $\mathrm{pH}$-sensitive oxygen-binding proteins (e.g., hemoglobin and hemocyanin). For example, the classic paper by Redfield and Goodkind (1929) shows that $\mathrm{CO}_{2}$ has no toxic effect on squids except "through its influence on the oxygenation of the blood." They demonstrate that asphyxiation in squids (Loligo pealei) occurs at a constant blood-oxygen level regardless of $\mathrm{CO}_{2}$, but that $\mathrm{CO}_{2}$ can influence the blood oxygen level. Thus, the blood oxygen level that causes asphyxiation is constant, but the environmental $P_{2}: P_{2}$ (i.e., the $\mathrm{RI}$ ) that results in that particular bloodoxygen level can be quite different. Extreme $\mathrm{pH}$ sensitivity of oxygen binding has been shown for a number of other squids (Bridges, 1994). The effect of $\mathrm{CO}_{2}$ on blood-oxygen binding is believed to be responsible for reduced levels of metabolism under ocean acidification scenarios in the squid, Dosidicus gigas (Rosa and Seibel, 2008; Seibel, 2013).

\section{Misleading predictions}

The Respiration Index results in inaccurate and potentially misleading predictions. For example, Brewer and Peltzer (2009) state that "for the vast areas of the ocean that are well-oxygenated, the rise in oceanic $\mathrm{CO}_{2}$ concentrations will exert a negligible effect on the normal aerobic functioning of adult marine animals." However, carbon dioxide may be most problematic in well-oxygenated surface waters because high temperature elevates oxygen demand above the 
limits of transport capacity (Rosa and Seibel, 2008). Conversely, the RI suggests that only very low $\mathrm{PO}_{2}(\mathrm{RI}<1)$ will limit marine animals. However, most marine organisms are poorly equipped for hypoxic conditions and become stressed at oxygen levels much higher than the limits proposed by Brewer and Peltzer (for instance, at an RI $\sim 2$; Vaquer-Sunyer and Duarte, 2008). Regions where oxygenminimum zones expand onto shelves may be particularly affected. For example, upwelled hypoxic water recently created a dead zone along the Oregon coast because the animals there are not equipped for low $\mathrm{PO}_{2}$ levels (Feely et al., 2008; Chan et al., 2008).

\section{What are the oxygen limits to marine life?}

Useful criteria for establishing limits for $\mathrm{O}_{2}$ tolerance must rely on measures of physiological or ecosystem performance and recognize the capacity of organisms to adjust $\mathrm{O}_{2}$ provision and demand, via acclimation and adaptation, to match oxygen availability. A measure of particular importance is the critical oxygen partial pressure $\left(P_{\text {crit }}\right.$; Grieshaber et al., 1994; Pörtner and Grieshaber, 1993; Childress and Seibel, 1998), which integrates the systems involved in oxygen uptake and transport with those that determine energy usage in whole animals (Connett et al., 1990; Pörtner and Knust, 2007). The $P_{\text {crit }}$ is defined as the oxygen partial pressure below which metabolism cannot be regulated independently of $\mathrm{PO}_{2}$ and may be indicated by either a reduction in oxygen consumption or an accumulation of anaerobic metabolites (e.g., lactate). Broad comparative studies have revealed that, below a "saturation threshold" ( $\sim 5 \mathrm{kPa}$; Seibel, 2011), the $P_{\text {crit }}$ closely matches the oxygen level to which a species is exposed in its natural range (Childress and Seibel, 1998; Seibel, 2011; Richards, 2011). This means that existing oxygen levels are the effective limit for marine life. Any reduction in $\mathrm{PO}_{2}$ from the current level requires acclimation, adaptation or migration, the capacity for which is unknown for most species. A lower "adaptation" threshold exists near $1 \mathrm{kPa}$, below which further reductions in oxygen do not elicit further reductions in $P_{\text {crit. }}$. In other words, an apparent limit to adaptation is reached beyond which further increase in gill surface area, blood oxygen affinity or ventilation capacity is not possible (Seibel, 2011). Ecosystems poised near this lower threshold, such as the California Current oxygen minimum zone, may undergo dramatic community restructuring with small reductions in oxygen content (Koslow et al., 2011).

Acknowledgements. I would like to thank the organizers of the EUR-OCEANS Conference - Ocean deoxygenation and implications for marine biogeochemical cycles and ecosystems for hosting a discussion of the Respiration Index.

Edited by: A. Paulmier

\section{References}

Bograd, S. J., Castro, C. G., Di Lorenzo, E., Palacios, D. M., and Bailey, H.: Oxygen declines and the shoaling of the hypoxic boundary in the California Current, Geophys. Res. Lett., 35, L12607, doi:10.1029/2008GL034185, 2008.

Brewer, P. G. and Peltzer, E. T.: Limits to marine life, Science, 324 , 347-348, 2009.

Bridges, C. R.: Bohr and root effects in cephalopod haemocyanins Paradox or pressure in Sepia officinalis. Physiology of cephalopod molluscs: lifestyle and performance adaptations, edited by: Portner, H.-O., O’Dor, R. K., and MacMillian, D. L., New York, NY, Gordon and Breach, 121-130, 1994.

Chan, F., Barth, J. A., Lubchenco, J., Kirincich, A., Weeks, H., Peterson, W. T., and Menge, B. A.: Emergence of anoxia in the California Current large marine ecosystem, Science, 319, p. 920, 2008.

Childress, J. J. and Seibel, B. A.: Life at stable low oxygen: adaptations of animals to oceanic oxygen minimum layers, J. Exp. Biol., 201, 1223-1232, 1998.

Connett, R. J., Honig, C. R., Gayeski, T. E., and Brooks, G. A.: Defining hypoxia: a systems view of $V \mathrm{O}_{2}$, glycolysis, energetics, and intracellular $\mathrm{PO}_{2}$, J. Appl. Physiol., 68, 833-842, 1990.

Feely, R. A., Sabine, C. L., Hernandez-Ayon, M. J., Ianson, D., and Hales, B.: Evidence for upwelling of corrosive "acidified" water onto the continental shelf, Science. 320, p. 1490, 2008.

Grieshaber, M. K., Hardewig, I., Kreutzer, U., and Pörtner, H. O.: Physiological and metabolic responses to hypoxia in invertebrates, Rev. Physiol. Bioch. P., 125, 43-147, 1994.

Hochachka, P. W. and Somero, G. N.: Biochemical Adaptation: Mechanism and Process in Physiological Evolution. Oxford: Oxford University Press, 2002.

Keeling, R. F., Körtzinger, A., and Gruber, N.: Ocean deoxygenation in a warming world, Annu. Rev. Mar. Sci., 2, 199-229, 2010.

Koslow, J. A., Goericke, R., Lara-Lopez, A., and Watson, W.: Impact of declining intermediate-water oxygen on deepwater fishes in the California Current, Mar. Ecol.-Prog. Ser., 436, 207-218, 2011.

Lehninger, A.: Principles of Biochemistry, edited by: Nelson, D. L. and Cox, M. M., W. H. Freeman, Publisher, 2008.

Melzner, F., Gutowska, M. A., Langenbuch, M., Dupont, S., Lucassen, M., Thorndyke, M. C., Bleich, M., and Pörtner, H.-O.: Physiological basis for high $\mathrm{CO}_{2}$ tolerance in marine ectothermic animals: pre-adaptation through lifestyle and ontogeny?, Biogeosciences, 6, 2313-2331, doi:10.5194/bg-6-2313-2009, 2009.

Pelster, B.: The generation of hyperbaric oxygen tensions in fish, Physiology, 16, 287-291, 2001.

Pörtner, H. O. and Grieshaber, M. K.: Critical $\mathrm{PO}_{2}(s)$ in oxyconforming and oxyregulating animals: gas exchange, metabolic rate and the mode of energy production, in: The vertebrate gas transport cascade: adaptations to environment and mode of life, edited by: Bicudo, J. E. P. W., CRC Press Inc., Boca Raton FL, USA, 330-357, 1993.

Pörtner, H. O. and Knust, R.: Climate change affects marine fishes through the oxygen limitation of thermal tolerance, Science, 315, 95-97, 2007.

Redfield, A. C. and Goodkind, R.: The significance of the Bohr effect in the respiration and asphysixiation of the squid, Loligo pealei, J. Exp. Biol., 6, 340-349, 1929. 
Richards, J. G.: Physiological, behavioral and biochemical adaptations of intertidal fishes to hypoxia, J. Exp. Biol., 214, 191-199, 2011.

Ries, J. B., Cohen, A. L., and McCorkle, D. C.: Marine calcifiers exhibit mixed responses to $\mathrm{CO}_{2}$-induced ocean acidification, $\mathrm{Ge}$ ology, 37, 1131-1134, 2009.

Rosa, R. and Seibel, B. A.: Synergistic effect of climate-related variables suggests future physiological impairment in a top oceanic predator, P. Natl. Acad. Sci., 52, 20776-20780, 2008.

Sanders, N. K. and Childress, J. J.: Comparison of the respiratory function of haemocyanins of vertically migrating and nonmigrating pelagic, deep-sea oplophorid shrimps, J. Exp. Biol., 152, 167-187, 1990.

Seibel, B. A.: Critical oxygen partial pressures and metabolic suppression in oxygen minimum zones, J. Exp. Biol., 214, 326-336, 2011.

Seibel, B. A.: The jumbo squid, Dosidicus gigas (Ommastrephidae), living in oxygen minimum zones II. Blood-oxygen binding, Deep-sea Res. Pt. II., in press, 2013.

Seibel, B. A. and Fabry, V. J.: Marine Biotic Response to Elevated Carbon Dioxide, Adv. Appl. Biodiv. Sci., 4, 59-67, 2003.

Seibel, B. A., Girguis, P. R., and Childress, J. J.: Variation in evolved "limits to life" preclude universal tolerance indices: a critique of the "Respiration Index", e-Letters, available at: http://www. sciencemag.org/cgi/eletters/324/5925/347\#12814, 2009.
Seibel, B. A., Maas, A. E., and Dierssen, H. M.: Energetic plasticity underlies variable response to ocean acidification in the Antarctic pteropod, Limacina helicina, PLoS One, 7, e30464, doi:10.1371/journal.pone.0030464, 2012.

Sidell, B.: Intracellular oxygen diffusion: the roles of myoglobin and lipid at cold body temperature, J. Exp. Biol., 201, 11191128, 1998.

Stramma, L., Johnson, G. C., Sprintall, J., and Mohrholz, V.: Expanding oxygen-minimum zones in the tropical oceans, Science, 320, 655-658, 2008.

Stumpp, M., Wren, J., Melzner, F., Thorndyke, M. C., and Dupont, S. T.: Seawater acidification impacts sea urchin larval development I: Elevated metabolic rates decrease scope for growth and induce developmental delay, Comp. Biochem. Physiol. A, 160, 331-340, 2011.

Vaquer-Sunyer, R. and Duarte, C. M.: Thresholds of hypoxia for marine biodiversity, P. Natl. Acad. Sci. USA, 105, 15452-15457, 2008. 